\title{
A New Evolutionary Method for Solving Combined Economic and Emission Dispatch
}

\author{
A. N. Afandi, Hajime Miyauchi \\ Computer Science and Electrical Engineering, GSST, Kumamoto University, Kumamoto, Japan \\ Email: an.afandi@ieee.org,miyauchi@cs.kumamoto-u.ac.jp
}

Received April, 2013

\begin{abstract}
This paper presents a new evolutionary method called in Harvest Season Artificial Bee Colony (HSABC) algorithm for solving constrained problems of Combined Economic and Emission Dispatch (CEED). The IEEE-30 bus system is adopted as a sample system for determining the best solutions of the CEED problems considering operational constraints. Running outs of designed programs for the HSABC show that applications of various compromised factors have different implications on the CEED's results, that minimum cost computations are started at different values, and that increasing load demands have affected costs, pollutant emissions and generated powers.
\end{abstract}

Keywords: Bees; Cost; Economic; Emission; Harvest; Minimum

\section{Introduction}

A power system is constructed by using interconnected structures for feeding an electric energy from generator sites to the some areas considering a sharing amount of a total power to meet a load demand at a certain period time of operation. One purpose of this strategy is to reduce the total technical operating cost through the combination various types of power plants. A minimizing cost problem of power system operation can be expressed by using an Economic Load Dispatch (ELD) for obtaining a minimum total fuel cost of generating units. In general, ELD's primary objective is to schedule the committed generating unit outputs to meet a certain load demand at a certain time under some operational constraints [1-3].

Presently, since the public awareness of the environmental protection has been increased to reduce atmospheric emissions, the ELD considers pollutant emissions in the air from combustions of fossil fuels at thermal power plants [4]. By considering an Emission Dispatch (EmD), the power system operation has to modify operational strategies of the thermal power plants for reducing pollutants in the air [5]. The ELD problem has become a crucial task to optimize a fuel cost with reducing a pollutant emission for scheduling the generating unit outputs based on a minimum total cost [6]. To avoid complexity problems of both dispatching types for determining solutions with difference targets, ELD and EmD are transformed into single objective function as a Combined Economic and Emission Dispatch (CEED).
Currently, many previous works have been successfully applied to solve the CEED problems [5,7-11]. The proposed methods have been introduced by using applications of mathematical programmings and optimization techniques [12]. Specifically, those methods can be devided into traditional and evolutionary types. Traditional methods cover several approaches such as linear programming, lagrangian relaxation, langrange multiplier and it can be applied to many problems [7,13-15]. On the other hand, evolutionary methods have become alternative ways to solve the problems. These methods are composed by using intelligent techniques for determining an optimum result like genetic algorithm, evolutionary programming, particles swarm optimization and neural network [5,16-20].

A novel computation of evolutionary methods is an Artificial Bee Colony (ABC) algorithm. This method was proposed by Karaboga in 2005 based on foraging behaviors of honeybees in nature [21]. This algorithm has abilities to overcome difficulties of evolutionary methods for solving real problems with multidimesional spaces and reducing time of computation [22-24]. These points are covered by using bee's interaction on the gathering and sharing information during searching the best solution. The ABC also has a powerful computation contrasted to other evolutionary methods, an ability to get out of a local and a global minimum, a capability of handling complex problems, and an effectiveness for solving optimizing problems $[4,6,25,26]$. The newest generation of this algorithm is a Harvest Season Artificial Bee Colony (HSABC) algorithm as a new evolutionary method. 
The HSABC is introduced in 2013 and it is composed by Multiple Food Sources (MFS) for mimicing flowers of a harvest season to provides candidate solutions of the problem [27].

This paper presents the HSABC for obtaining the best solution of the CEED problems. The objective function of the CEED is subjected to some operational constraints. In these works, IEEE-30 bus system is adopted as a sample system for the simulations.

\section{Problem Statement}

\subsection{Combined Economic and Emission Dispatch}

A problem of ELD is related to a nonlinear equation [28]. The ELD's objective function is expressed by a total cost for providing a total power from generation stations and it can be computed by using equation (1). Presently, an ELD includes a pollutant emission as a constraint. Various pollutants have been come from the burning of fossil fuels in the thermal power plants $[8,9,14]$. The total pollutant emission is formulated by equation (2) as the EmD. The ELD and EmD are composed into single objective function of CEED problem with considering a price penalty [8] and a weighting factor as a compromised factor [5] as formed in equation (4). The penalty factor shows the rate coefficient of each generating unit at its maximum output for the given load. The compromised factor shows a sharing contribution of ELD and EmD. Several limitations for performing CEED are given by equation (5) to (10). Specifically, a total transmission loss is not constant and it depends on the power outputs of generating units $[28,29]$. The transmission loss can be appeared from a load flow analysis. In general, the CEED problem can be formulated by using expressions as follows:

$$
\begin{aligned}
& \text { ELD minimize } \mathrm{F}_{\mathrm{tc}}=\sum_{\mathrm{i}=1}^{\mathrm{ng}}\left(\mathrm{c}_{\mathrm{i}}+\mathrm{b}_{\mathrm{i}} \cdot \mathrm{P}_{\mathrm{i}}+\mathrm{a}_{\mathrm{i}} \cdot \mathrm{P}_{\mathrm{i}}^{2}\right) \text {, } \\
& \text { EmD minimize } E_{t}=\sum_{i=1}^{n g}\left(\gamma_{i}+\beta_{i} \cdot P_{i}+\alpha_{i} \cdot P_{i}^{2}\right) \text {, } \\
& h_{i}=\frac{F_{i}\left(p_{i}^{\max }\right) / p_{i}^{\text {max }}}{E_{i}\left(p_{i}^{\text {max }}\right) / p_{i}^{\text {max }}}, \\
& \text { CEED minimize } \Phi=w \cdot F_{t c}+(1-w) \cdot h \cdot E_{t} \text {, } \\
& \sum_{\mathrm{i}=1}^{\mathrm{ng}} \mathrm{P}_{\mathrm{i}}=\mathrm{P}_{\mathrm{D}}+\mathrm{P}_{\mathrm{L}} \text {, } \\
& P_{G p}=P_{D p}+V_{p} \sum_{q=1}^{n B u s} V_{q}\left(G_{p q} \cdot \cos \theta_{p q}+B_{p q} \cdot \sin \theta_{p q}\right) \text {, } \\
& \mathrm{Q}_{\mathrm{Gp}}=\mathrm{Q}_{\mathrm{Dp}}+\mathrm{V}_{\mathrm{p}} \sum_{\mathrm{q}=1}^{\mathrm{nBus}} \mathrm{V}_{\mathrm{q}}\left(\mathrm{G}_{\mathrm{pq}} \cdot \sin \theta_{\mathrm{pq}}-\mathrm{B}_{\mathrm{pq}} \cdot \cos \theta_{\mathrm{pq}}\right) \text {, } \\
& \mathrm{P}_{\mathrm{i}}^{\min } \leq \mathrm{P}_{\mathrm{i}} \leq \mathrm{P}_{\mathrm{i}}^{\max } \text {, } \\
& \mathrm{Q}_{\mathrm{i}}^{\min } \leq \mathrm{Q}_{\mathrm{i}} \leq \mathrm{Q}_{\mathrm{i}}^{\max }, \\
& \mathrm{V}_{\mathrm{p}}^{\min } \leq \mathrm{V}_{\mathrm{p}} \leq \mathrm{V}_{\mathrm{p}}^{\max }
\end{aligned}
$$

where $P_{i}$ is output power of $i^{\text {th }}$ generating unit (MW), $a_{i}$, $b_{i}, c_{i}$ are fuel cost coefficients of $i^{\text {th }}$ generating unit, $F_{t c}$ is total fuel cost $(\$ / \mathrm{hr}), \alpha_{\mathrm{i}}, \beta_{\mathrm{i}}, \gamma_{\mathrm{i}}$ are emission coefficients of $\mathrm{i}^{\text {th }}$ generating unit, $\mathrm{E}_{\mathrm{t}}$ is total emission of generating units $(\mathrm{kg} / \mathrm{hr}), \mathrm{h}_{\mathrm{i}}$ is individual penalty factor of $\mathrm{i}^{\text {th }}$ generating unit, $\mathrm{P}_{\mathrm{i}}{ }^{\max }$ is maximum output power of $\mathrm{i}^{\mathrm{th}}$ generating unit, $E_{i}$ is total emission of $i^{\text {th }}$ generating unit $(\mathrm{kg} / \mathrm{hr}), F_{i}$ is fuel cost of $i^{\text {th }}$ generating unit $(\$ / h r), \Phi$ is CEED ( $\left.\$ / h r\right)$, w is compromised factor, ng is number of generator, $\mathrm{h}$ is penalty factor of ascending order selection of $h_{i}, P_{D}$ is power load demand, $\mathrm{P}_{\mathrm{L}}$ is transmission loss, $\mathrm{P}_{\mathrm{Gp}}$ and $\mathrm{Q}_{\mathrm{Gp}}$ are power injections of load flow at bus $p, \mathrm{P}_{\mathrm{Dp}}$ and $\mathrm{Q}_{\mathrm{Dp}}$ are load demands of load flow at bus $p, V_{p}$ and $V_{q}$ are voltages at bus $\mathrm{p}$ and $\mathrm{q}, \mathrm{P}_{\mathrm{i}}^{\min }$ is minimum power of $\mathrm{i}^{\text {th }}$ generating unit, $\mathrm{Q}_{\mathrm{i}}^{\max }$ and $\mathrm{Q}_{\mathrm{i}}^{\min }$ are maximum and minimum reactive powers of $i^{\text {th }}$ generating unit, $V_{p}{ }^{\max }$ and $\mathrm{V}_{\mathrm{p}}{ }^{\mathrm{min}}$ are maximum and minimum voltages at bus $\mathrm{p}$.

\subsection{Harvest Season Artificial Bee Colony}

The HSABC algorithm is composed by MFS to presents many flowers of the harvest season located randomly at certain positions in the harvest season area [27]. Specifically, HSABC is inspired by a harvest season situation in nature for providing flowers. In the HSABC, a flower is presented by a food source and MFS express many flowers. To exploit food sources, bees fly randomly during foraging for the foods and the position moves from a selected current food source to another one [25,30]. In the HSABC, MFS are consisted by the First Food Source (FFS) and Other Food Sources (OFS). Each position of OFS is directed by a harvest operator (ho) from the FFS. A set of OFS is preceded by foraging for the FFS. As in the $A B C$, the HSABC has four phases for searching the best food as a final solution, those are initial phase, employed bees phase, onlooker bees phase and scout bees phase.

An initial phase is a set population generation of candidate solutions. This population is created randomly by considering the constraints. For each solution is corresponded to the number of parameter to be optimized which populated using equation (11). An employed bees phase is a searching mechanism of a neighbor food source. Each food source chosen represents a possible solution to the problem. The new food source is searched by an employed bee as the FFS. After the FFS is found by bee, OFS have been created to express the harvest season situation. An onlooker bees phase is a food source selection for the best food. Onlooker bee chooses a food source based on the probability value each nectar quality. The nectar quality is evaluated by using equation (14) and probability of each food source is determined by using equation (15). Each position of candidate food is searched by using equation (12) for the FSS and it is accompanied by OFS using equation (13). A scout bees phase is a random searching for a new food source used to replace an abandoned value. 
In general, the rules of the HSABC are a set of MFS is consisted by FFS and OFS, the FSS is followed by OFS, every food source is located at a different position, all food sources stay in the harvest season area, colony size is consisted by employed bees and onlooker bees, an employed bee of an abandoned food source becomes a scout bee. By mathematical expressions, the HSABC are presented as following expressions:

$$
\begin{aligned}
& x_{i j}=x_{\text {minj }}+\operatorname{rand}(0,1) *\left(x_{\operatorname{maxj}}-x_{\text {minj }}\right) \text {, } \\
& v_{i j}=x_{i j}+\phi_{i j} \cdot\left(x_{i j}-x_{i j}\right) \text {, } \\
& \mathrm{H}_{\mathrm{iho}}= \begin{cases}\mathrm{x}_{\mathrm{kj}}+\emptyset_{\mathrm{ij}}\left(\mathrm{x}_{\mathrm{kj}}-\mathrm{x}_{\mathrm{fj}}\right) \cdot(\text { ho }-1), & \text { for } \mathrm{R}_{\mathrm{j}}<\mathrm{MR} \\
\mathrm{x}_{\mathrm{kj}}, & \text { otherwise }\end{cases} \\
& \text { fit }_{\tilde{\mathrm{i}}}=\left\{\begin{array}{c}
\frac{1}{1+\mathrm{F}_{\mathrm{i}}}, \text { for } \mathrm{F}_{\mathrm{i}} \geq 0 \\
1+\mathrm{abs}\left(\mathrm{F}_{\tilde{\mathrm{i}}}\right), \text { if } \mathrm{F}_{\tilde{\mathrm{i}}} \leq 0
\end{array},\right. \\
& \mathrm{p}_{\mathrm{i}}=\frac{\mathrm{fit}_{\mathrm{i}}}{\sum_{\mathrm{i}=1}^{\mathrm{SN}} \text { fit }_{\mathrm{i}}} \text {. }
\end{aligned}
$$

where $x_{i j}$ is a current food, $i$ is the $i^{\text {th }}$ solution of the food source, $j \in\{1,2,3, \ldots, D\}, D$ is the number of variables of the problem, $x_{\operatorname{minj}}$ is minimum limit of $x_{i j}, x_{\operatorname{maxj}}$ is maximum limit of $x_{i j}, v_{i j}$ is food position, $x_{k j}$ is random neighborof $\mathrm{x}_{\mathrm{ij}}, \mathrm{k} \in\{1,2,3, \ldots, \mathrm{SN}\}, \mathrm{SN}$ is the number of solutions, $\varnothing_{\mathrm{i}, \mathrm{j}}$ is a random number within $[-1,1], \mathrm{H}_{\mathrm{iho}}$ is harvest season food position, ho $\in\{2,3, \ldots, F T\}$, FT is the total number of flowers for harvest season, $\mathrm{x}_{\mathrm{fj}}$ is random harvest neighborof $x_{k j}, f \in\{1,2,3, \ldots, S N\}, R_{j}$ is a randomly chosen real number within $[0,1]$, MR is modified rate of probability food, $F_{i}$ is objective function of the $i^{\text {th }}$ solution of the food, fit $\mathrm{i}_{\mathrm{i}}$ is fitness value of the $\mathrm{i}^{\text {th }}$ solution and $\mathrm{p}_{\mathrm{i}}$ is probability of the $\mathrm{i}^{\text {th }}$ quality of food.

\section{Sample System and Procedures}

In these simulations, parameters listed in Table 1 to Table 3 are used for the sample system. Figure 1 shows the single line diagram of IEEE-30 bus system.

Designed programs of application HSABC for solving CEED problems are created by considering several steps of HSABC's procedures as presented in Figure 2. The listing programs are categorized into three programs. The data input program is consisted by a set data of parameters for generating units, transmission lines, loads, constraints, CEED's parameters and HSABC's parameters. The CEED program is designed for an objective function to compute a minimum total cost based on the CEED problem, compromised factors and constraints. The HSABC program is developed by using HSABC's steps for searching the best solution of the CEED problem.

\section{Results and Discussions}

These works are addressed to solve the CEED problem using HSABC algorithm for obtaining the best solution
Table 1. Fuel cost coefficients and mw limits.

\begin{tabular}{ccccccc}
\hline Bus & Gen & $\begin{array}{c}\mathrm{a} \\
\left(\$ / \mathrm{MWh}^{2}\right)\end{array}$ & $\begin{array}{c}\mathrm{b} \\
(\$ / \mathrm{MWh})\end{array}$ & $\mathrm{c}$ & $\begin{array}{c}\mathrm{P}_{\min } \\
(\mathrm{MW})\end{array}$ & $\begin{array}{c}\mathrm{P}_{\max } \\
(\mathrm{MW})\end{array}$ \\
\hline 1 & $\mathrm{G} 1$ & 0.00375 & 2.00000 & 0 & 50 & 200 \\
2 & $\mathrm{G} 2$ & 0.01750 & 1.75000 & 0 & 20 & 80 \\
5 & $\mathrm{G} 3$ & 0.06250 & 1.00000 & 0 & 15 & 50 \\
8 & $\mathrm{G} 4$ & 0.00835 & 3.25000 & 0 & 10 & 35 \\
11 & $\mathrm{G} 5$ & 0.02500 & 3.00000 & 0 & 10 & 30 \\
13 & $\mathrm{G} 6$ & 0.02500 & 3.00000 & 0 & 12 & 40 \\
\hline
\end{tabular}

Table 2. Emission coefficients and mvar limits.

\begin{tabular}{cccccc}
\hline Gen & $\begin{array}{c}\alpha \\
\left(\mathrm{kg} / \mathrm{MWh}^{2}\right)\end{array}$ & $\begin{array}{c}\beta \\
(\mathrm{kg} / \mathrm{MWh})\end{array}$ & $\gamma$ & $\begin{array}{c}\mathrm{Q}_{\min } \\
(\text { Mvar })\end{array}$ & $\begin{array}{c}\mathrm{Q}_{\max } \\
(\mathrm{Mvar})\end{array}$ \\
\hline G1 & 0.0126 & -1.1000 & 22.9830 & 100 & -100 \\
G2 & 0.0200 & -0.1000 & 25.3130 & 60 & -60 \\
G3 & 0.0270 & -0.0100 & 25.5050 & 65 & -15 \\
G4 & 0.0291 & -0.0050 & 24.9000 & 50 & -15 \\
G5 & 0.0290 & -0.0040 & 24.7000 & 40 & -10 \\
G6 & 0.0271 & -0.0055 & 25.3000 & 15 & -15 \\
\hline
\end{tabular}

Table 3. Load data for each bus.

\begin{tabular}{cccccc}
\hline Bus No & MW & Mvar & Bus No & MW & Mvar \\
\hline 1 & 0.0 & 0.0 & 16 & 3.5 & 1.8 \\
2 & 21.7 & 12.7 & 17 & 9.0 & 5.8 \\
3 & 2.4 & 1.2 & 18 & 3.2 & 0.9 \\
4 & 7.6 & 1.6 & 19 & 9.5 & 3.4 \\
5 & 94.2 & 19.0 & 20 & 2.2 & 0.7 \\
6 & 0.0 & 0.0 & 21 & 17.5 & 11.2 \\
7 & 22.8 & 10.9 & 22 & 0.0 & 0.0 \\
8 & 30.0 & 30.0 & 23 & 3.2 & 1.6 \\
9 & 0.0 & 0.0 & 24 & 8.7 & 6.7 \\
10 & 5.8 & 2.0 & 25 & 0.0 & 0.0 \\
11 & 0.0 & 0.0 & 26 & 3.5 & 2.3 \\
12 & 11.2 & 7.5 & 27 & 0.0 & 0.0 \\
13 & 0.0 & 0.0 & 28 & 0.0 & 0.0 \\
14 & 6.2 & 1.6 & 29 & 2.4 & 0.9 \\
15 & 8.2 & 2.5 & 30 & 10.6 & 1.9 \\
\hline
\end{tabular}

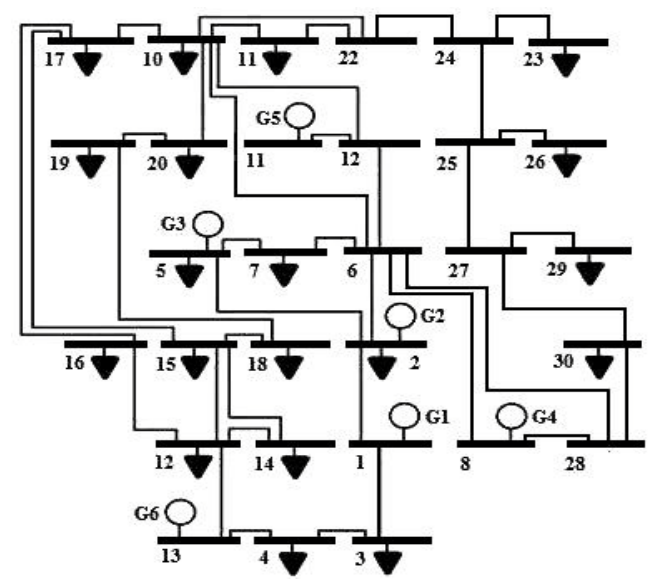

Figure 1. One-line diagram of IEEE 30 bus system. 


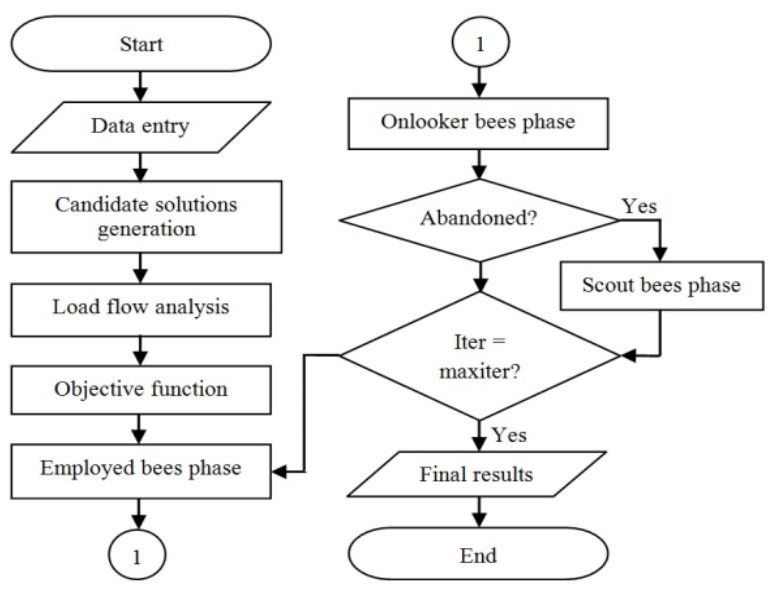

Figure 2. HSABC's flow chart for solving CEED problem.

and determining a committed power outputs of generating units. The main purpose of the used compromised factors is to know the best combination of ELD and EmD from possibility values of combinations. To observe HSABC's performances on load demand changes are studied in this section. Effects of load demand changes are also evaluated on the sample system.

These studies consider 283.4 MW of load demand, \pm $5 \%$ of voltage limits, power balance and power limits. The programs are executed by using colony size $=100$, number of foods $=50$, limit number of foods $=50$, total foraging cycles $=100$ and 3 flowers. An initial population of a set candidate food is presented in Figure 3 as the candidate solutions for six generating units. The best food of each food source is located at random positions as shown in Figure 4. Determined iterations on the CEED's minimum cost are presented in Table 4 and Figure 5.

Final solutions of the committed power outputs of generating units to meet a load demand at the minimum total costs are listed in Table 5 and final minimum operating costs are provided in Table 6. Power losses and pollutant emissions are presented in Figure 7. By considering combinations of ELD and EmD, according to Table 6 and Figure 5, better results are obtained by using $\mathrm{w}$ $=0.5$. For this chase, the CEED has the shortest range from a starting cost to reaches a minimum cost, the cheapest total cost is given by using $\mathrm{w}=0.5$ and the fastest convergence speed is also performed by using this compromised factor as presented in Figure 5. The convergence speed of the CEED used $\mathrm{w}=0.5$ is illustrated in Figure 6.

Practically, generating units are associated with load demand behaviors during operations. To performs load demand changes and evaluates it in the total cost are studied in these works. For these works, a sharing contribution of ELD and EmD use 0.5 of compromised factor. Load demands are assumed to increase gradually at load buses. The performances on increased load demands are listed in Table 7. By comparing costs in Table 7 to Table 6 for column $\mathrm{w}=0.5$, the percentage results are given in Table 8.

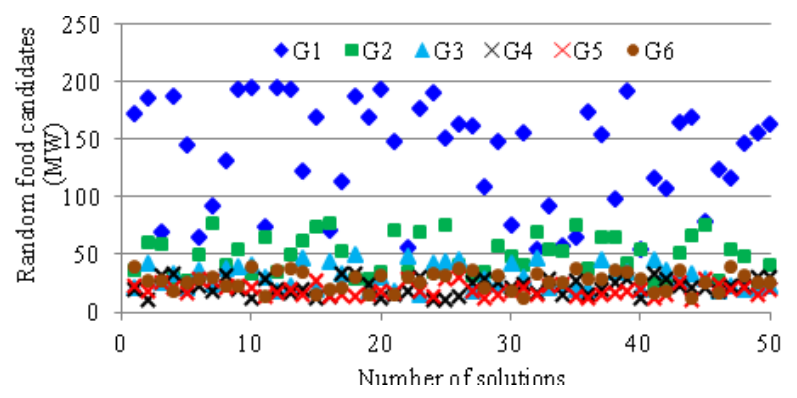

Figure 3. Populations of candidate solutions.

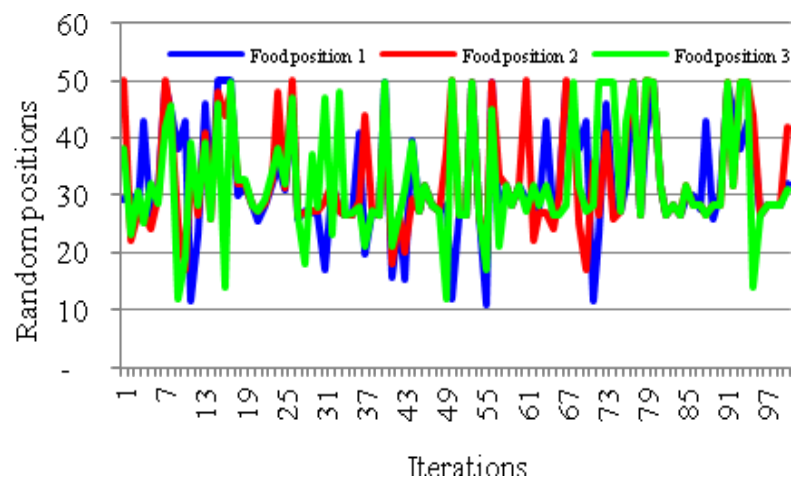

Figure 4. Food positions of food sources.

Table 4. CEED's minimum of the computations.

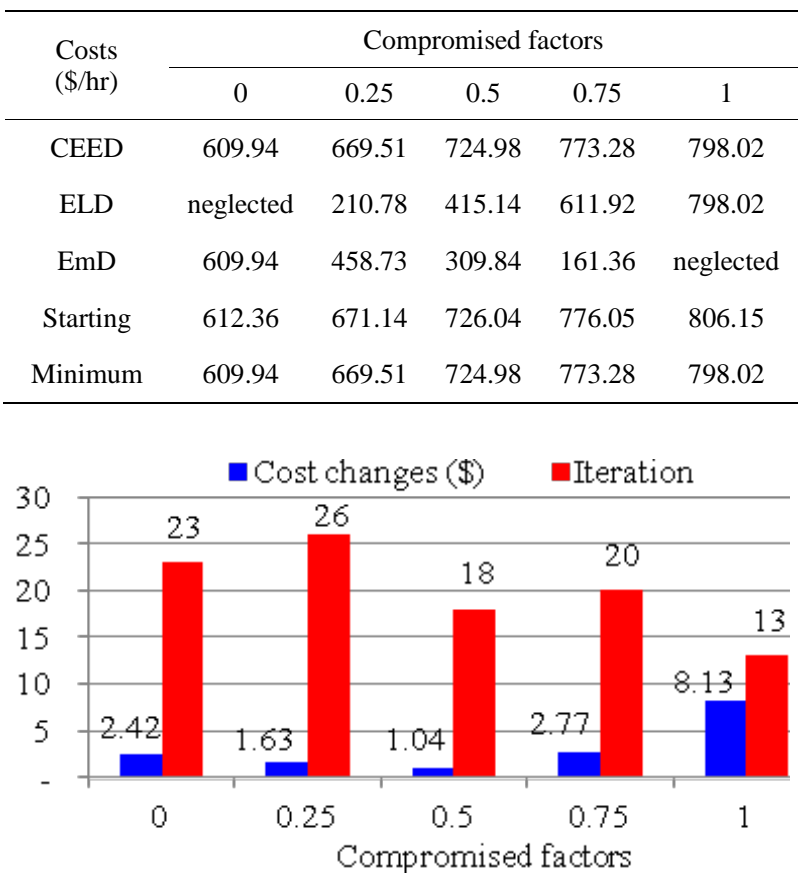

Figure 5. Cost changes and iterations at CEED's minimum. 
Table 5. Final result of committed power outputs.

\begin{tabular}{cccccc}
\hline \multirow{2}{*}{$\begin{array}{c}\text { Subjects } \\
\text { (MW) }\end{array}$} & \multicolumn{5}{c}{ Compromised factors } \\
\cline { 2 - 6 } & 0 & 0.25 & 0.5 & 0.75 & 1 \\
\hline G1 & 112.29 & 117.60 & 126.07 & 140.68 & 177.46 \\
G2 & 46.96 & 48.26 & 49.74 & 50.66 & 49.35 \\
G3 & 34.87 & 31.48 & 28.40 & 25.25 & 19.63 \\
G4 & 31.48 & 31.66 & 31.80 & 30.90 & 22.83 \\
G5 & 30.00 & 29.54 & 26.63 & 21.74 & 12.11 \\
G6 & 33.29 & 30.71 & 27.17 & 21.54 & 12.00 \\
Total power & 288.89 & 289.25 & 289.81 & 290.77 & 293.38 \\
Total loss & 5.49 & 5.85 & 6.41 & 7.37 & 9.98 \\
\hline
\end{tabular}

Table 6. Final result of minimum total costs.

\begin{tabular}{cccccc}
\hline \multirow{2}{*}{$\begin{array}{c}\text { Subjects } \\
(\$ / h r)\end{array}$} & \multicolumn{5}{c}{ Compromised factors } \\
\cline { 2 - 6 } & 0 & 0.25 & 0.5 & 0.75 & 1 \\
\hline Fuel cost & 854.11 & 843.10 & 830.28 & 815.89 & 803.89 \\
Emis. cost & 610.07 & 611.76 & 619.81 & 645.57 & 765.87 \\
Total cost & 1464.18 & 1454.86 & 1450.09 & 1461.46 & 1569.76 \\
\hline
\end{tabular}

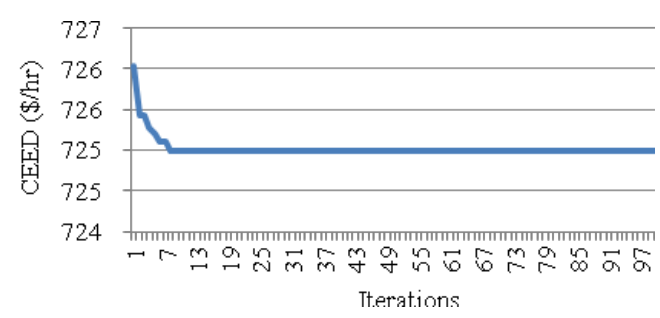

Figure 6. Convergence speed using $w=0.5$.

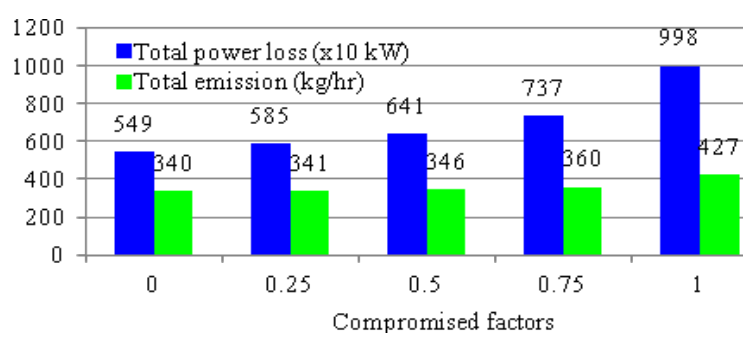

Figure 7. Final results of emissions and power losses.

Table 7. Final results on various loads.

\begin{tabular}{lccc}
\hline \multirow{2}{*}{\multicolumn{1}{c}{ Subjects }} & \multicolumn{3}{c}{ Increased load demands (MW) } \\
\cline { 2 - 4 } & $20 \%$ & $30 \%$ & $40 \%$ \\
\hline G1 (MW) & 150.84 & 165.76 & 182.73 \\
G2 (MW) & 62.08 & 69.86 & 78.78 \\
G3 (MW) & 34.44 & 38.53 & 43.20 \\
G4 (MW) & 35.00 & 35.00 & 35.00 \\
G5 (MW) & 30.00 & 30.00 & 30.00 \\
G6 (MW) & 36.59 & 40.00 & 40.00 \\
Total G (MW) & 348.95 & 379.15 & 409.71 \\
Loss (MW) & 8.87 & 10.73 & 12.95 \\
T. Emission (kg/hr) & 469.55 & 547.48 & 639.21 \\
T. Emission Cost $(\$ / h r)$ & 841.24 & 980.89 & 1145.20 \\
T. Fuel Cost $(\$ / h r)$ & 1051.37 & 1170.00 & 1293.45 \\
T. Cost $(\$ / h r)$ & 1892.61 & 2150.89 & 2438.65 \\
\hline
\end{tabular}

Table 8. Percentage results on various loads.

\begin{tabular}{cccc}
\hline \multirow{3}{*}{ Subjects } & \multicolumn{3}{c}{ New load demands } \\
\cline { 2 - 4 } & $\begin{array}{c}340.08 \mathrm{MW} \\
(20 \%)\end{array}$ & $\begin{array}{c}368.42 \mathrm{MW} \\
(30 \%)\end{array}$ & $\begin{array}{c}396.76 \mathrm{MW} \\
(40 \%)\end{array}$ \\
\hline Fuel costs & 0.2663 & 0.4092 & 0.5578 \\
Emis. Costs & 0.3573 & 0.5826 & 0.8477 \\
Total cost & 0.3052 & 0.4833 & 0.6817 \\
\hline
\end{tabular}

From Table 7 is known that all power outputs of combined generating units are produced up by increased load demands. Specifically, G5 and G4 feed to the power system with $30 \mathrm{MW}$ and $35 \mathrm{WM}$ because of upper power limits. Generating units produces 348.95 MW to 409.71 MW of total powers with increasing losses from 8.87 MW to $12.95 \mathrm{MW}$. The most interesting point is $40 \%$ of increased load demand. In this case, all components of cost exceed $50 \%$ as listed in Table 8. The higher load demand associates with greater payments of generating unit.

\section{Conclusions}

This paper presents an application of a new evolutionary method, Harvest Season Artificial Bee Colony Algorithm, for solving CEED problem using IEEE-30 bus as a sample system. These works demonstrate that compromised factors give effects to the CEED's solutions. These studies indicate that increasing load demands affect generated power outputs, pollutant emissions and costs. By considering compositions of ELD and EmD, the lowest total cost is obtained by CEED using 0.5 of compromised factor. In these simulations, the HSABC is tested on a standard model of IEEE, a revealing real sample system is devoted to the future works.

\section{Acknowledgements}

The authors gratefully acknowledge the support and thanks to Kumamoto University (Japan) and Beasiswa Luar Negeri DIKTI (Indonesia).

\section{REFERENCES}

[1] H. Chahkandi Nejad, 1R. Jahani, 1M. Mohammad Abadi, "GAPSO-based Economic Load Dispatch of Power System”, Australian Journal of Basic and Applied Sciences, Vol. 5, No.7, 2011, pp. 606-611.

[2] M. A. Abido, "Multiobjective Evolutionary Algorithms for Electric Power Dispatch Problem," IEEE Transactions on Evolutionary Computation, Vol. 10, No. 3, 2006, pp. 315-329. doi:10.1109/TEVC.2005.857073

[3] S. Sayah, K. Zehar, "Economic Load Dispatch with Security Constraints of the Algerian Power System Using Successive Linear Programming Method," Leonardo Journal of Science, No. 9, 2006, pp. 73-86. 
[4] Y. Z. Cheng, W. P. Xiao, W.-J. Lee and M. Yang, “A New Approach for Missions and Security Constrained Economic Dispatch", Proc. NAPS, IEEE Conference Publication, Starkville USA, 4-6 Oct 2009, pp. 1-5.

[5] M. A. Abido, "Enviranmental/economic Power Dispatch Using Multiobjective Evolutionary Algorithm," IEEE Transactions Power Systems, Vol. 18, No. 4, 2003, pp. 1529-1537. doi:10.1109/TPWRS.2003.818693

[6] F. S. Abu-Mouti and M. E. El-Hawary, "Optimal Distributed Generation Allocation and Sizing in Distribution System via Artificial Bee Colony Algorithm," IEEE Journal \& Magazines, Vol. 26, No. 4, 2011, pp. 2090-2101.

[7] A. A. El-Keib, H. Ma and J. L. Hart, "Environmentally Constrained ED Using the Lagrangian Relaxation Method”, IEEE Trans. Power Systems, Vol. 9, Issue. 4, 1994, pp. 1723-1729. doi:10.1109/59.331423

[8] K. Sathish Kumar, V. Tamilselvan, N. Murali, R. Rajaram, N. Shanmuga Sundaram and T. Jayabarathi, "Economic Load Dispatch with Emission Constraints Using Various PSO Algorithm," WSEAS Transaction on Power System, Vol. 3, No. 9, 2008, pp. 598-607.

[9] R. Gopalakrishnan and A. Krishnan, “A Novel Combined Economic and Emission Dispatch Problem Solving Technique Using Non-dominated Ranked Genetic Algorithm,” European Journal of Scientific Research, Vol. 64, No. 1, 2011, pp. 141-151.

[10] Y. Fu, M. Shahidehpour, Z. Y. Li : “AC Contingency Dispatch Based on Security Constrained Unit Commitment”, IEEE Transactions on Power Systems, Vol. 21, pp. 897-908 (2006). doi:10.1109/TPWRS.2006.873407

[11] Yong Fu, Mohammad Shahidehpour, Zuyi Li, "Security Constrained unit Commitment with AC Constraints," IEEE Transactions Power Systems, Vol. 20, No. 3, 2005, pp. 1538-1550. doi:10.1109/TPWRS.2005.854375

[12] B. H. Chowdhury and S. Rahman, "A Review of Recent Advances in Economic Dispatch," IEEE Transactions on Power Systems, Vol. 5, No. 4, 1990, pp. 1248-1259. doi:10.1109/59.99376

[13] A. Farag, S. Al-Baiyat and T. C. Cheng, "Economic Load Dispatch Multiobjective Optimization Procedures Using Linear Programming Techniques,” IEEE Transactions Power Systems, Vol. 10, No. 2, 1995, pp. 731-738. doi:10.1109/59.387910

[14] M. Garg and S. Kumar, “A Survey on Environmental Economic Load Dispatch Using Lagrange Multiplier Method," International Journal of Electronics \& Communication Technology, Vol. 3, No. 1, 2012, pp. 43-46.

[15] S. Subramanian and S. Ganesa, "A Simplified Approach for ED with Piecewise Quadratic Cost Functions,” International Journal of Computer and Electrical Engineering, Vol. 2, No. 5, 2010, pp. 793-798.

[16] I. G. Damausis, A. G. Bakirtzis and P. S. Dokopoulos, "Network Constrained Economic Dispatch Using Real Coded Genetic Algorithm," IEEE Transaction Power
Systems, Vol. 18, No. 1, 2003, pp. 198-205. doi:10.1109/TPWRS.2002.807115

[17] M. A. Aziz, J. I. Musirin and T. K. A. Rahman, "Solving dynamic ED using evolutionary programming”, Proc. First International Power and Energy Conference, Putra Jaya, 28-29 Nov 2006, pp. 144-149.

[18] T. Yalcinoz and M. J. Short, "Large-scale ED using an improved hopfield neural network", IEE Proc. Gener. Transm. Distrib, Vol. 144, Issue. 22, 1997, pp. 181-185. doi:10.1049/ip-gtd:19970866

[19] Y. Abdelaziz, S. F. Mekhamer, M. A. L. Badr, and M. Z. Kamh, "ED using an enhanced hopfield neural network", Electric Power Components and Systems, Vol. 36, No. 7, 2008, pp. 719-732. doi:10.1080/15325000701881969

[20] Z.-L. Gaing, "Particle Swarm Optimization to Solving the ED Considering the Generator Constraints," IEEE Transactions Power Systems, Vol. 18, No. 3, 2003, pp.1187-1195.doi:10.1109/TPWRS.2003.814889

[21] D. Karaboga, “An Idea Based on Honey Bee Swarm for Numerical Optimization”, Technical Report-TR06, Erciyes University, Turkey, 2005.

[22] M. Subotic, “Artificial Bee Colony Algorithm for Constrained Optimization Problems Modified with Multiple Onlookers," International Journal and Mathematical Models and Methods in Applied Sciences, Vol. 6, No. 2, 2012, pp.314-322.

[23] N. Stanarevic, M. Tuba and N. Bacanin, "Modified Artificial Bee Colony Algorithm for Constrained Problems Optimization”, International Journal of Mathematical Models and Methods in Applied Science, Vol. 5, No. 3, 2011, pp. 644-651.

[24] E. M. Montes, M. D. Araoz and O. C. Dominges, "Smart Flight and Dynamic Tolerances in the Artificial Bee Colony for Constrained Optimization," Proc. IEEE Congress on Evolutionary Computation CEC , Barcelona, 18-23 July 2010, pp. 1-8. doi:10.1109/CEC.2010.5586099

[25] D. Karaboga and B. Basturk, “A Powerful and Efficient Algorithm for Numerical Function Optimization: ABCAlgorithm,” Journal of Global Optimization, Vol. 39, No. 0925-5001, 2007, pp. 459-471.

[26] C. C. Columbus and S. P. Simon, "A Parallel ABC for Security Constrained Economic Dispatch Using Shared Memory Mmodel,” Proc. 2012 EPSCICON IEEE Conference Publication, Thrissur Kerala, 3-6 Jan 2012, pp. 1-6.

[27] A. N. Afandi and H. Miyauchi, "Multiple Food Sources for Composing Harvest Season Artificial Bee Colony Algorithm on Economic Dispatch Problem," Proc. The 2013 Annual Meeting of the IEEJ, Nagoya, 20-22 March 2013, No. 6-008, pp. 11-12.

[28] H. Saadad, “Electric Power System,” Mc. Graw Hill, New York, 1999.

[29] H. Shayeghi and A. Ghasemi, “Application of MOFSO for Economic Load Dispatch Solution with Transmission Losses,” IJTPE Journal, Vol. 4, No. 1, 2012, pp. 27-34. 